FOLIA

Amazónico

Revista del Instituto de Investigaciones

de la Amazonía Peruana

\title{
ANÁLISIS ESPACIAL DE LA DEFORESTACIÓN POR ACTIVIDAD PETROLERA EN EL LOTE 192, LORETO, PERÚ
}

\author{
Juan J. PALACIOS VEGA ${ }^{1}$, Werner CHOTA-MACUYAMA², Ricardo ZÁRATE GÓMEZ, \\ Pedro E. PÉREZ PEÑA ${ }^{3}$
}

1 Instituto de Investigaciones de la Amazonía Peruana. Dirección de Investigación en Sociedades Amazónicas; Av. Quiñones km 2,5, San Juan Bautista, Maynas, Loreto, Perú. Correo electrónico: jpalacios@iiap.gob.pe

2 Instituto de Investigaciones de la Amazonía Peruana. Dirección de Investigación en Ecosistemas Acuáticos Amazónicos; Av. Quiñones km 4,5, San Juan Bautista, Maynas, Loreto, Perú.

3 Instituto de Investigaciones de la Amazonía Peruana. Dirección de Investigación en Diversidad Biológica Terrestre Amazónica. Av. Quiñones km 2,5, San Juan Bautista, Maynas, Loreto, Perú.

\section{RESUMEN}

El departamento de Loreto cuenta con abundantes reservas de petróleo, cuya explotación genera impactos ambientales en esta parte de la Amazonía. Los productos de desecho de esta actividad son vertidos directamente a los ríos, teniendo como efectos la alteración de las aguas, los bosques, la fauna y la salud de las poblaciones aledañas. Actualmente es importante contar con información oportuna sobre la cuantificación y distribución de los impactos que genera la actividad petrolera en la región. El presente estudio tuvo como objetivo cuantificar la deforestación y evaluar su relación con los derrames petroleros en el Lote 192 utilizando imágenes del satélite Landsat 5 y 7 para el periodo 19862005 en Loreto, Perú. Se generó información sobre la deforestación utilizando imágenes de satélite históricas del sensor Landsat 5 TM y 7 ETM+ y reportes de vertidos de crudo en el Lote 192 mediante análisis espacial en Sistemas de Información Geográfica (SIG). La mayor deforestación ocurrió en el periodo 1993 a 1996 con la pérdida de 8 661,20 hectáreas debido al vertimiento de desechos de la actividad petrolera. El derrame de petróleo influenció en la deforestación del Lote 192, específicamente en el bosque de colina baja.

PALABRAS CLAVE: Amazonía peruana, contaminación ambiental, derrame de petróleo, Google Earth Engine, petróleo crudo. 


\title{
SPATIAL ANALYSIS OF DEFORESTATION BY OIL ACTIVITY IN LOT 192, LORETO, PERU
}

\begin{abstract}
The Loreto department has abundant oil reserves, whose exploitation generates environmental impacts in this part of the Amazon. The waste products of this activity are dumped directly into the rivers, with the effects of altering the waters, the forests, fauna and the health of the surrounding populations. Currently it is important to have timely information on the quantification and distribution of impacts generated by oil activity in the región. It is important to have information on the quantification and distribution of the impacts generated by oil activity in the region. The objective of the present study was to quantify deforestation in Block 192 and evaluate the relationship between oil spills and deforestation in Block 192 using Landsat 5 and 7 satellite images for the period 1986-2005 in Loreto, Peru. Information on deforestation was generated using historical satellite images from the Landsat 5 TM and 7 ETM + sensors and reports of oil spills in Block 192 through spatial analysis in Geographic Information Systems (GIS). The greatest deforestation occurred in the period 1993 to 1996 with the loss of 8661.20 hectares due to the dumping of waste from oil activities. The oil spill influenced deforestation in Block 192 specifically in the low hill forest.
\end{abstract}

KEYWORDS: Peruvian Amazon, environmental pollution, oil spill, Google Earth Engine, crude oil. 


\section{INTRODUCCIÓN}

El petróleo es la principal fuente de energía de la sociedad desde comienzos del siglo XX y aún en la actualidad la demanda mundial continúa aumentando (Organization of Petroleum Exporting Countries, 2018). El aumento en la demanda sobre todo, en países en desarrollo, ha incrementado el interés y la necesidad de acceder a nuevos yacimientos de hidrocarburos (Finer \& Orta-Martínez, 2010). La explotación del petróleo se realiza también en zonas remotas en los bosques húmedos tropicales que cuentan con elevado valor para la conservación biológica, cultural y paisajística (Butt et al., 2013).

La Amazonía Occidental es la región de mayor biodiversidad de la cuenca amazónica, donde todavía existen vastas zonas de ecosistemas intactos y la mayor densidad de grupos étnicos con algunos grupos indígenas que permanecen en aislamiento voluntario (Rosell-Melé et al., 2017). Sin embargo, es la región con mayor avance de la explotación de petróleo debido a las grandes reservas de hidrocarburos presentes. Aunque la explotación petrolera en la Amazonía peruana alcanzó su máximo en la década de 1970, se ha observado en los últimos años un nuevo boom de exploración y extracción de hidrocarburos (Finer \& Orta-Martínez, 2010) en paralelo a la creciente demanda mundial del recurso (Organization of Petroleum Exporting Countries, 2018).

Durante el proceso de extracción del crudo, las aguas de formación representan el 70\% del volumen total extraído de un pozo petrolero (Fakhru'l-Razi et al., 2009). Estas aguas contienen grandes concentraciones de cloruros, hidrocarburos aromáticos, y metales pesados como el plomo, cadmio o mercurio entre otros (Neff, 2002). En la Amazonía peruana, las aguas de formación derivados de la actividad petrolera fueron inicialmente vertidas directamente a los ríos como productos de desecho. Sin embargo, a partir de enero de 2008 se implementó el Decreto Supremo $\mathrm{N}^{\circ}$ 002-2008 MINAM (Ministerio del Ambiente, 2008), cesando el vertido de aguas de formación e iniciando el reinyectado de los vertidos en pozos petroleros vacíos (Powers, 2008).

A pesar de ello, como resultado de inspecciones de la zona por parte de las autoridades competentes, en el 2013, el gobierno peruano declaró en estado de emergencia ambiental a las cuencas de los ríos Pastaza (Ministerio del Ambiente, 2013a), Corrientes (Ministerio del Ambiente, 2013b), y Tigre (Ministerio del Ambiente, 2013c), y en emergencia sanitaria a las localidades de las tres cuencas en el 2014. La elevada concentración de metales pesados en los ríos fue finalmente aceptado como riesgo para la salud y la vida de los pobladores amazónicos (Yusta et al., 2015). Por ello es importante poder contar con información sobre los impactos que causa la explotación de los hidrocarburos, no solo sobre la salud de la población sino también sobre los bosques. A nivel de gobierno y sectores competentes, no se cuenta con este tipo de información, limitando la priorización de nuevas propuestas de manejo de las aguas de formación y más aún del manejo de los constantes derrames de petróleo reportados en la región.

Las imágenes de sensores remotos montados en satélites que orbitan la tierra son herramientas muy útiles para monitorear un territorio y determinar los cambios históricos en la cobertura de los bosques (Palacios et al., 2019). Estos cambios pueden ser contrastados con información secundaria de los posibles impactos reportados de una actividad para el mapeo de la sensibilidad y distribución de los impactos causado por ejemplo por los derrames de petróleo (Ivanov \& Zatyagalova, 2008; Kankara et al., 2016).

Las imágenes de algunos sensores como Landsat 5 TM y 7 ETM+ presentan resolución espacial de $30 \mathrm{~m}$, y son útiles para extraer algunos 
índices de salud de la vegetación utilizando modelos de análisis de datos tipo machine learning (Ozigis et al., 2019). Se ha demostrado el potencial del análisis espectral de las imágenes de satélite Landsat para diferenciar áreas de cobertura vegetal de aquellas que no la tienen (Cardoso et al., 2014), así mismo, para evaluar daños en la cobertura del bosque se utiliza el Índice de Vegetación de Diferencia Normalizada (NDVI) en series de tiempo o comparando los valores de NDVI en dos tiempos, lo cual implica en la importancia de este índice en estudios de perturbaciones ecológicas por derrames de petróleo (Millward \& Kraft, 2004; Ozigis et al., 2019). La disminución de los valores del NDVI en un entorno de bosque es un indicador del impacto sobre la cobertura del bosque (Gandhi et al., 2015), este índice es posible calcularlo a partir de valores de reflectancia contenidos en los pixeles de las imágenes Landsat y permite monitorear los cambios por derrames de petróleo y sus principales impactos (Mo et al., 2017).

Por lo cual, el objetivo del presente estudio fue cuantificar la deforestación en el Lote 192 y evaluar la relación entre los derrames petroleros y deforestación, utilizando imágenes del satélite Landsat 5 y 7 para el periodo 1986 - 2005 en Loreto, Perú.

\section{MATERIAL Y MÉTODOS}

\section{ÁREA DE ESTUDIO}

El área de estudio comprende el lote petrolero 192, el cual se encuentra situado al noroeste de la región de Loreto, en los distritos de Andoas de la provincia Datem del Marañón; y Trompeteros y Tigre de la provincia Loreto, en las cuencas de los ríos Pastaza, Corrientes y Tigre. Contiene a 20 centros poblados con una población total de 3503 habitantes y 889 viviendas según el censo de población y vivienda del año 2017 (Figura 1). Este lote cubre un área de 498 185,59 ha, limita por el norte con la republica del Ecuador, al noreste con los lotes 39 y 67, al sur con el lote 8 y al sur oeste con el lote 64. La explotación petrolera en el lote 192 comenzó en el año 1971 (Finer \& Orta-Martínez, 2010) a manos de la petrolera Occidental Petroleum Corporation del Perú (OXY). Posteriormente, en el año 2001, la concesión pasó a manos de la empresa argentina Pluspetrol Corporation S.A. (luego Pluspetrol Norte S.A.) de acuerdo a Orta et al. (2007). Desde agosto del 2015, la empresa que opera en el lote es Pacific Stratus Energy del Perú Sociedad Anónima. El lote 192 fue uno de los más productivos del Perú, con una extracción de 120000 barriles de petróleo por día en el año 1982 junto con otros lotes suponían el $67 \%$ de la extracción petrolera del Perú (Orta-Martínez \& Finer, 2010). Entre 1971 y 2016, el lote 192 ha producido 709778 millones de barriles de crudo obtenidos en un total de 247 pozos (Ministerio de Energía y Minas, 2017). En el Lote 192 se presentan ocho tipos de vegetación, y los más dominantes son los bosques de colina baja y terraza baja con un total de 481259 ha que corresponden el 96\% de la superficie del área de estudio (MINAM, 2015).

\section{DATOS, MATERIALES Y PROGRAMAS UTILIZADOS}

Se recopilaron datos satelitales utilizando el editor de código de la plataforma Google Earth Engine (GEE) de las colecciones de datos satelitales Landsat 5 TM y 7 ETM+ con reflectancia superficial corregida atmosféricamente de 30 metros de resolución espacial, ortorrectificadas y de los años 1986, 1990, 1993, 1996, 1997, 1999, 2001, 2004, 2005. No se utilizaron imágenes de los otros años debido a que presentaban un porcentaje mayor al $20 \%$ de cobertura de nubes para el área de estudio.

Se utilizaron capas vectoriales de ubicación de los pozos y 74 registros de coordenadas de 
Figura 1: Ubicación del área de estudio, Lote 192, Loreto, Perú.

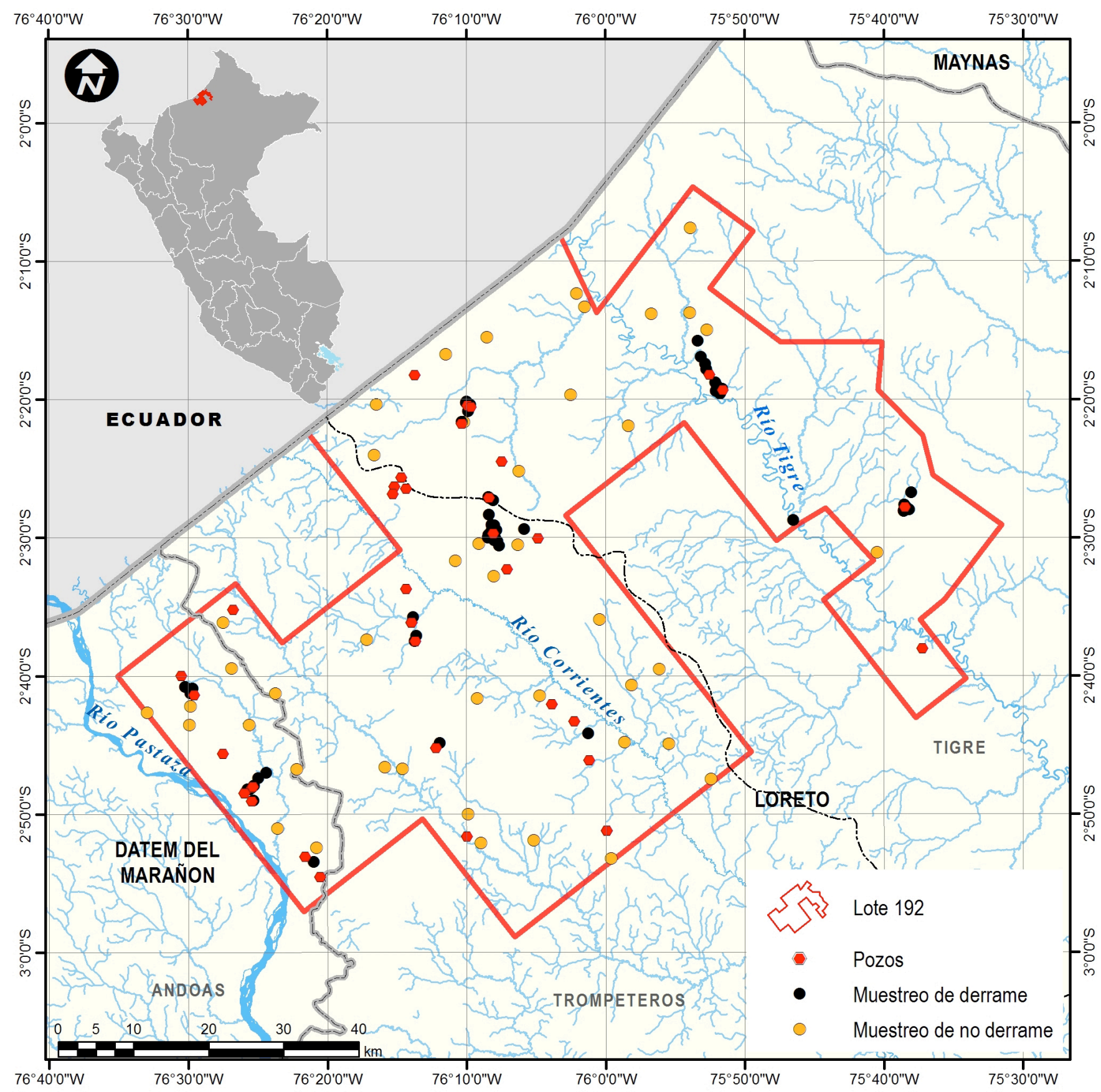


Figura 2: Deforestación y ubicación de las pozos petroleros en el Lote 192, Loreto, Perú.

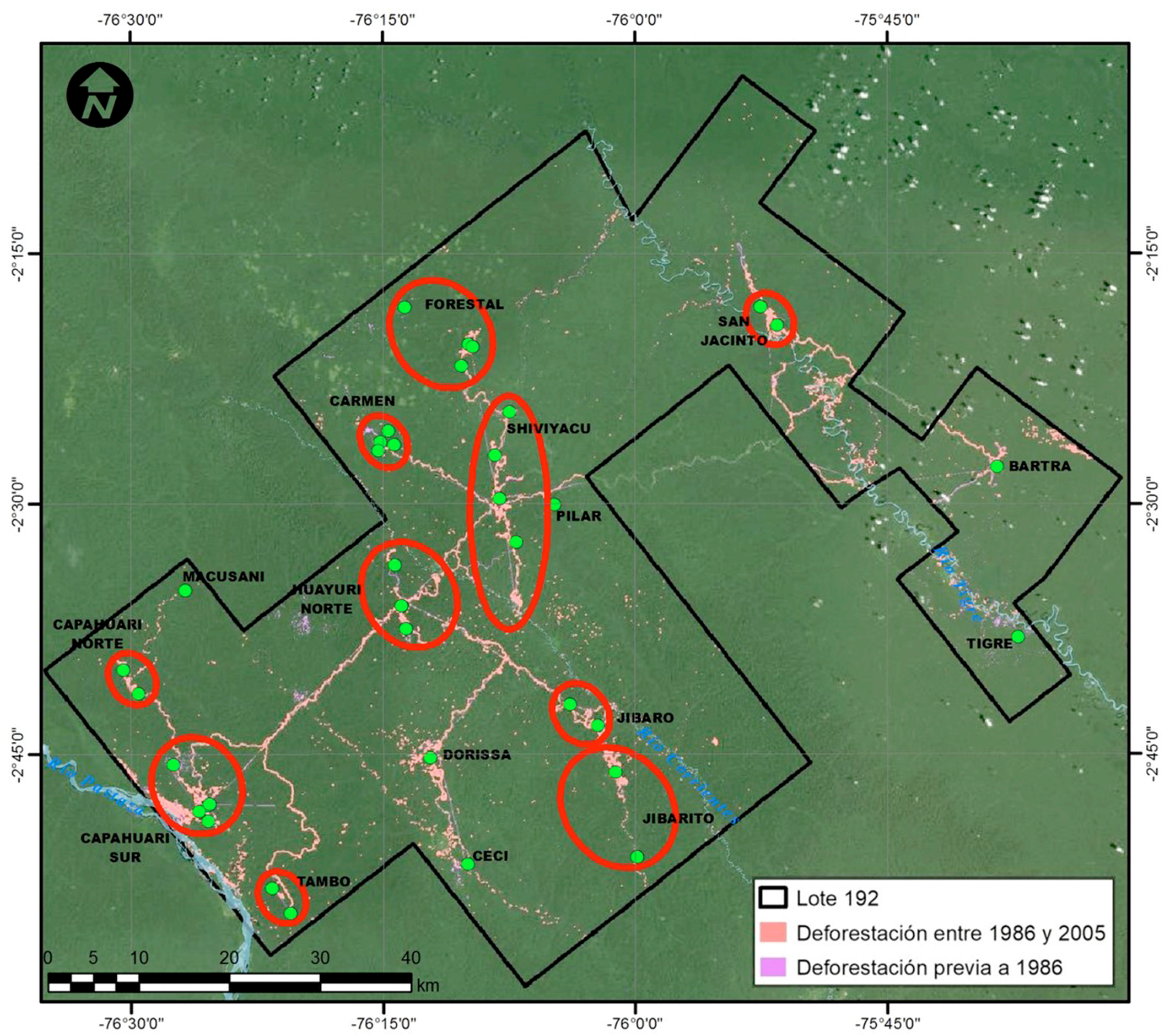

ubicación de emergencias por derrames de crudo, reportados por la empresa Pluspetrol Norte Sociedad Anónima durante el año 2004.

Para el análisis del NDVI y su relación con los tipos de cobertura vegetal se utilizó la capa de información vectorial del "Mapa de Vegetación del Perú" (MINAM, 2015).
El programa ArcMAP v10.1 se utilizó para el análisis de la geoinformación y composición de los mapas. Toda la información procesada y los resultados de los análisis estuvieron referidos al Sistema Geodésico Mundial WGS 84 y proyección en el Sistema Universal Transversal de Mercator (UTM) Zona 18 Sur. 
PROCESAMIENTO DE IMÁGENES, MASCARA DE SOMBRAS Y NUBES, Y EXTRACCIÓN DE CUERPOS DE AGUA

Se enmascaró las zonas afectadas por nubes y sombras utilizando la banda de calidad de la imagen de satélite mediante un proceso automático. Luego se realizó un enmascaramiento de los cuerpos de agua aplicando el Índice de Agua Normalizado Modificado (MNDWI; Xu, 2006), según la ecuación MNDWI=( $\rho$ GREEN- $\rho$ MIR)/ $(\rho$ GREEN $+\rho$ MIR) en donde $\rho$ GREEN se refiere a la reflectancia TOA de la banda espectral del verde y $\rho$ MIR, a la banda espectral del infrarrojo medio. Para obtener un mejor resultado en el proceso de enmascaramiento de los cuerpos de agua se generó un buffer de 30 metros, de tal manera que la máscara de agua corresponda también a los primeros 30 metros de las zonas adyacentes al cuerpo de agua.

\section{CÁLCULO DE LA DEFORESTACIÓN CON EL} NDVI

La deforestación generada por la actividad extractiva del petróleo en el Lote 192 se calculó mediante la extracción del Índice de Vegetación de Diferencia Normalizada (NDVI), para cada una de las nueve imágenes Landsat enmascaradas, utilizando la ecuación NDVI $=(\rho \mathrm{NIR}-\rho \mathrm{R}) /$ $(\rho N I R+\rho R)$ en donde $\rho$ NIR se refiere a la reflectancia TOA de la banda espectral del infrarrojo cercano y $\rho \mathrm{R}$ a la banda espectral del rojo (Gandhi et al., 2015; Palacios et al., 2019). Posteriormente se normalizó los valores entre los máximos y mínimos de los datos de las capas de información raster de NDVI con la finalidad de compararlas entre ellas y minimizar las diferencias entre los valores de NDVI.

\section{DEFORESTACIÓN CON NDVI EN EL PERIODO 2004-2005}

Para efectos del análisis se eligieron las imágenes de NDVI del 2004 y 2005 por ser el periodo en el cual se reportaron las emergencias por derrame de crudo. Los datos calculados fueron de la detección del cambio en la cobertura del bosque, se utilizaron 44 de los 74 registros de derrames de crudo y 47 registros de lugares en los cuales no hubo ningún tipo de derrame ni influencia del mismo. Las muestras fueron generadas a partir de la diferencia promedio de los valores de NDVI calculados para los años 2004 y 2005 de los nueve pixeles vecinos por cada punto de los registros elegidos para el análisis. Así mismo, con los 44 puntos elegidos se extrajo mediante una unión espacial los tipos de cobertura de bosque del Mapa de Vegetación del Perú. Seguidamente, se identificaron aquellas zonas en las cuales el valor del índice se redujo de forma significativa, representando las áreas en las que disminuyó superficie de cobertura vegetal (Palacios et al., 2019).

Para determinar las variables (mínimo, promedio, máximo, sumatoria de los valores de la diferencia del NDVI entre los 9 pixeles aledaños al punto del derrame petrolero) que pueden ayudar a medir la deforestación por derrame de petróleo se aplicó un análisis de componentes principales. Luego para determinar si la deforestación cambió por el derrame de petróleo utilizamos la prueba de ANOSIM con un nivel de confianza del $95 \%$. Y para medir el impacto del derrame petrolero en la deforestación del mismo tipo de vegetación, utilizamos la prueba Mann-Whitney.

\section{RESULTADOS}

\section{PROCESAMIENTO DE IMÁGENES LANDSAT}

Las imágenes de satélite de los años 1986, 2004 y 2005 presentaron mayor nubosidad en el área de estudio, con cobertura de sombras que representan el 19,8 \% en la imagen del 1986, $23,3 \%$ en la imagen de 2005, y $24,0 \%$ en la imagen del 2004. El resto de imágenes presentó 
Tabla 1. Superficie de máscara de nubes y sombras de imágenes Landsat 5 y 7

\begin{tabular}{cccc}
\hline Fecha & Número de polígonos & Superficie (ha) & $\%$ del Lote 192 \\
\hline $26 / 04 / 1986$ & 2072 & 98598,69 & $19,8 \%$ \\
$26 / 07 / 1990$ & 167 & 2675,70 & $0,5 \%$ \\
$23 / 11 / 1993$ & 27 & 4287,19 & $0,9 \%$ \\
$11 / 08 / 1996$ & 3 & 98,06 & $0,0 \%$ \\
$30 / 08 / 1997$ & 916 & 19487,74 & $3,9 \%$ \\
$20 / 08 / 1999$ & 2 & 5263,96 & $1,1 \%$ \\
$05 / 01 / 2001$ & 3 & 8592,85 & $1,7 \%$ \\
$02 / 09 / 2004$ & 881 & 119351,65 & $24,0 \%$ \\
$24 / 01 / 2005$ & 440 & 115977,87 & $23,3 \%$ \\
\hline
\end{tabular}

Tabla 2. Superficie de máscara de cuerpos de agua.

\begin{tabular}{|c|c|c|c|}
\hline Fecha & Número de polígonos & Superficie (ha) & \% del Lote 192 \\
\hline 26/04/1986 & 463 & 4049,28 & $0,8 \%$ \\
\hline 26/07/1990 & 577 & 5075,35 & $1,0 \%$ \\
\hline 23/11/1993 & 486 & 4711,61 & $0,9 \%$ \\
\hline 11/08/1996 & 568 & 5020,33 & $1,0 \%$ \\
\hline 30/08/1997 & 331 & 4209,05 & $0,8 \%$ \\
\hline 20/08/1999 & 344 & 4034,49 & $0,8 \%$ \\
\hline 05/01/2001 & 552 & 4782,46 & $1,0 \%$ \\
\hline 02/09/2004 & 525 & 4915,87 & $1,0 \%$ \\
\hline 24/01/2005 & 302 & 2182,43 & $0,4 \%$ \\
\hline
\end{tabular}


menos del $4 \%$ de cobertura de nubes y sombras (Tabla 1).

Así también, se observa que la superficie de cuerpos de agua entre los años 1986 al 2004 representan el 0,8 - 1 \% del área de estudio, excepto el año 2005 cuando la superficie de agua se redujo a $0,4 \%$ (Tabla 2 ) debido principalmente a la distribución de la cobertura de nubes y sombras sobre la imagen de ese año.

\section{DEFORESTACIÓN O PÉRDIDA DE COBERTURA} EN EL LOTE 192

De acuerdo con el análisis de la variación multitemporal del NDVI, el total de superficie deforestada al año 1986 fue de 5 782,20 ha, representando una pérdida de $1,16 \%$ del área estudio. La pérdida de cobertura se dio principalmente por la construcción de la red de carreteras, oleoductos, campamentos, las baterías de Shiviyacu y Jibarito, y la estación recolectora Nuevo Andoas (Figura 2). Al año 2005 la pérdida de cobertura por deforestación llegó a un total de 12 104,70 ha representando el 2,43 \% del Lote 192 (Tabla 3), correspondiendo a las baterías de Huayuri, Dorisa y Capahuari Sur.

El análisis de componentes principales identificó dos variables que pueden ayudar a medir cambios en la pérdida de cobertura boscosa después de un derrame de petróleo: la pérdida máxima, y la pérdida acumulada (sumatoria). Esta explicación se da al 99,18 \% en dos dimensiones, en donde la primera dimensión explica al 97,65 \% y la segunda al 2,12 \% (Figura 3). La diferencia de las variables de pérdida debosques entre zonas con y sin derrame son significativas (ANOSIM=0,073, $\mathrm{P}=0,003)$. Por otra parte, los tipos de vegetación (hábitats) no tienen el mismo impacto después de un derrame de acuerdo a la prueba de MannWhitney. El bosque de colina baja sin derrame naturalmente pierde 0.027 ha, pero con derrame pierde 0,075 ha $(\mathrm{U}=167, \mathrm{P}<0,001)$, es decir, pierde casi el triple de bosque. Por otro lado, la pérdida
Tabla 3. Superficie deforestada y perturbada en el periodo 1986-2005.

\begin{tabular}{lcc}
\hline \multirow{2}{*}{ Año } & \multicolumn{2}{c}{ Deforestación } \\
\cline { 2 - 3 } & Superficie (ha) & \% del Lote 192 \\
\hline 1986 & 5782,20 & 1,16 \\
1990 & 6595,90 & 1,32 \\
1993 & 8005,50 & 1,61 \\
1996 & 8661,20 & 1,74 \\
1997 & 9410,10 & 1,89 \\
1999 & 9796,50 & 1,97 \\
2001 & 10740,90 & 2,16 \\
2004 & 11229,90 & 2,25 \\
2005 & 12104,70 & 2,43 \\
\hline
\end{tabular}

del bosque de terraza baja sin derrame es de 0,037 ha pero con derrame es de 0.050 ha, esta diferencia no es significativa $(\mathrm{U}=33, \mathrm{P}=0,348)$. Es decir, el derrame de petróleo afecta más al bosque de colina baja a pesar que experimenta naturalmente más ganancia de bosque cuando no hay derrame de petróleo (Figura 4).

\section{DISCUSIÓN}

El análisis de imágenes de satélite calculando índices espectrales ha permitido identificar $y$ cuantificar la superficie de bosque deforestada causada por la actividad de explotación del petróleo en el Lote 192. Los resultados muestran que al 2005 se ha perdido 2874,10 ha de la cobertura boscosa $(0,56 \%$ de la superficie del Lote 192) debido a la construcción de vías de acceso, instalación de pozos y derrames de petróleo que causan la muerte de los árboles o pérdida del vigor del bosque. Nuestros resultados son coherentes con los obtenidos en el 2015 en 
Figura 3: Análisis de Componentes Principales (ACP) y ANOSIM de la pérdida del bosque entre zonas sin (cuadros azules) y con derrame (cuadros rojos). La longitud y orientación de las flechas verdes indican la mayor importancia de la variable.

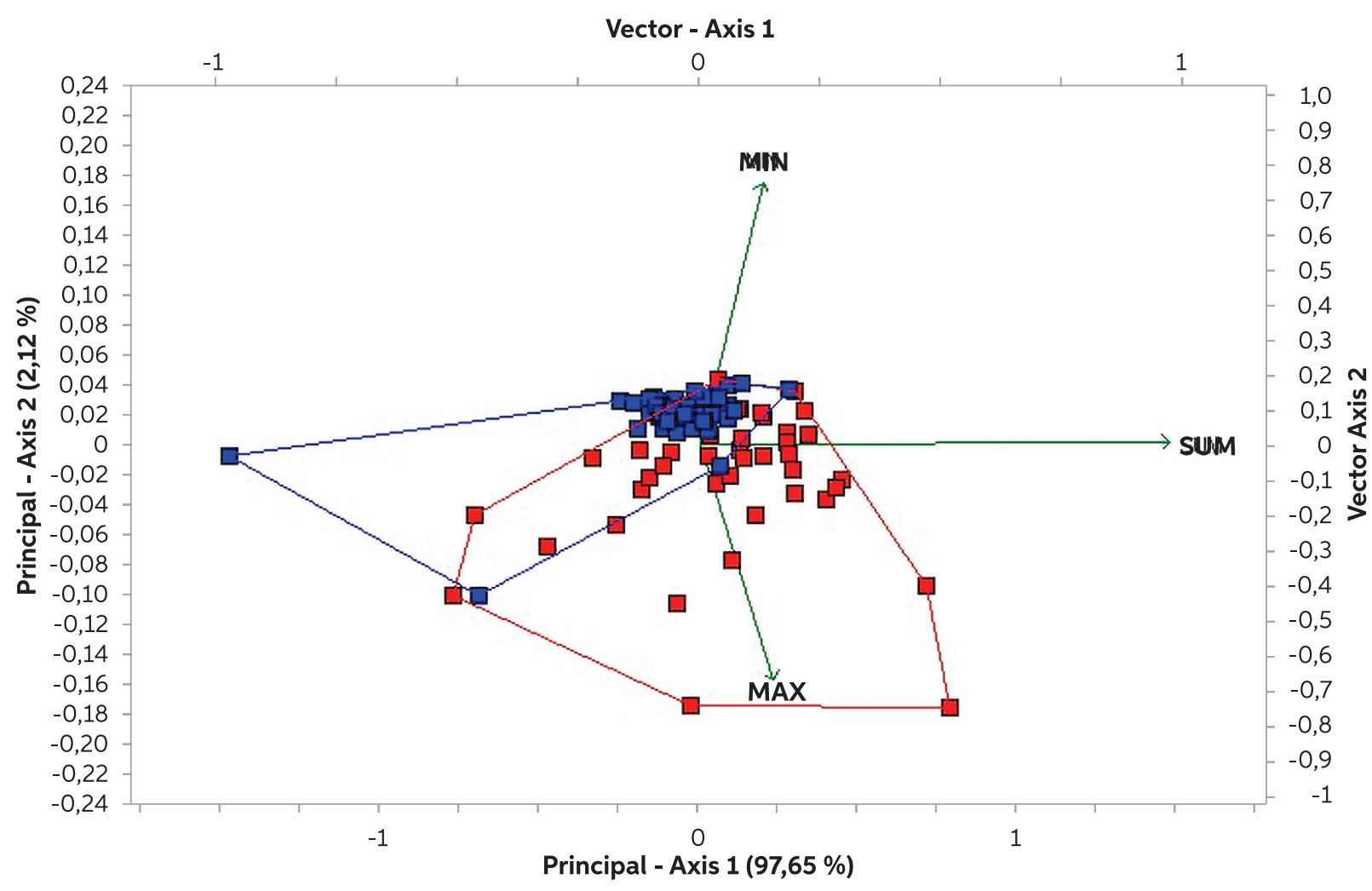

Figura 4: Comparación de la pérdida o ganancia de bosque entre los bosques de colina baja y terraza baja durante el derrame de petróleo.

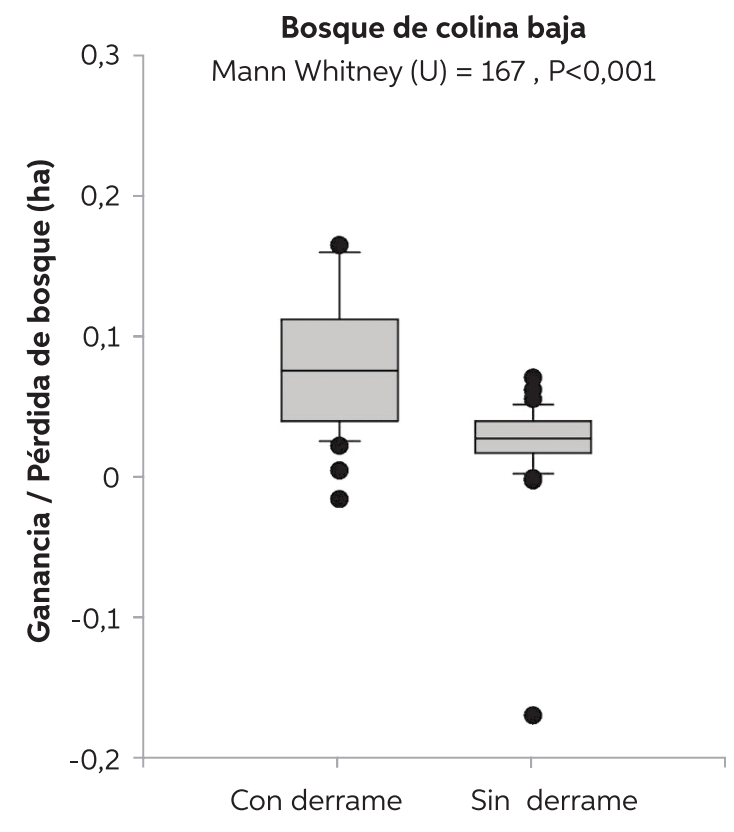

Bosque de terraza baja

Mann Whitney $(U)=33, P<0,348$

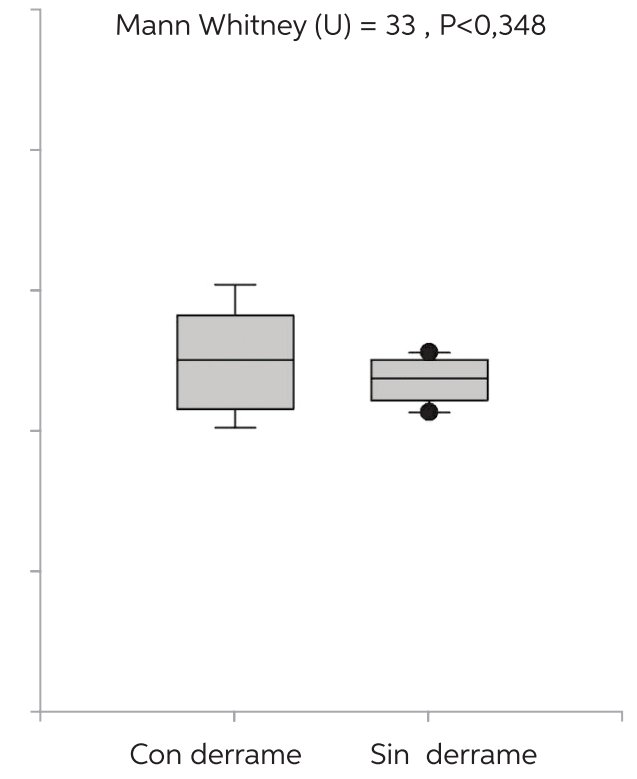


la batería de Yanayacu del Lote 8 en la Reserva Nacional Pacaya Samiria, donde reportan una pérdida de 746,45 ha del bosque debido también a la apertura de rutas de acceso, aguas de formación y derrames de petróleo (Yusta et al., 2015). Mediante el estudio de la variación del NDVI se ha observado que frecuentemente una misma zona puede mostrar un incremento negativo del NDVI en el tiempo. Este fenómeno se debe a una progresiva deforestación del terreno o bien a sucesivas tareas de mantenimiento de las carreteras y oleoductos tras periodos en los cuales existe una cierta recuperación de la cobertura por crecimiento de la vegetación secundaria.

La pérdida y la alteración de la cobertura del bosque debido a la deforestación tienen consecuencias negativas en la flora y fauna (Rojas, 2020). La apertura de vías de comunicación como carreteras afectan al ecosistema ya que actuan como barreras infranqueable por varias especies (Laurance et al., 2009).

Nuestros resultados indican que el derrame de petróleo influye en la disminución de la cobertura boscosa, resultados similares encontraron Yusta et al. (2015) para un sector dentro de la Reserva Nacional Pacaya Samiria en la Amazonía peruana, Albert et al. (2018) en el bosque tropical en Nigeria, Duke et al. (1997) para los bosques de manglares caribeños en Panamá. Entonces esto no solo está pasando en la Amazonía peruana, y los derrames de petróleo también son motores de la deforestación, tanto dentro de la Amazonía peruana como en otras partes. Debemos considerar a los derrames de petróleo como causantes importantes de la deforestación, y no solo a la agricultura y ganadería (Armenteras \& Rodríguez, 2014; Dourojeanni, 2016), ya que las áreas deforestadas por derrame de petróleo no se recuperan al mismo ritmo que los otros tipos de intervención y finalmente ya no secuestran carbono atmosférico, aumentando su impacto con el pasar del tiempo.

La deforestación por derrame de petróleo se basa en la influencia negativa que ejerce este en la fisiología y anatomía de las plantas. Afecta en la cantidad de germinación, retrasa la germinación, impide el crecimiento (Ekundayo et al., 2001; Ogbo et al., 2009), disminuye la cantidad de clorofila e impide el paso de la luz por la cutícula (Baruah et al., 2014).

Algo pendiente es desarrollar modelos espaciales de distribución de derrames de petróleo en la Amazonía, esto permitirá tener una mejor idea de las áreas deforestadas por los derrames de petróleo y del impacto que está causando; estos modelos solo están desarrollados para derrames de petróleo en el mar (Brekke \& Solberg, 2005; Brenner, 2015; Nelson \& Grubesic, 2020; Yekeen et al., 2020); pero aún falta desarrollar para la Amazonía. Se pueden usar índices en un sistema de monitoreo para detectar la contaminación de petróleo, ya que actualmente hay muchas mejoras en la tecnología (Arellano et al., 2017). Pero lamentablemente los estudios científicos publicados sobre derrames de petróleo en la Amazonía peruana son muy escasos, lo cual dificulta abordar esta problemática en la región.

\section{AGRADECIMIENTOS}

Al Programa Nacional de Innovación para la Competitividad y Productividad (Innóvate Perú) por el financiamiento de las actividades que conllevaron a la elaboración del presente artículo, a través del proyecto "Impacto de vertidos petrogénicos sobre el ecosistema y la fauna acuática en la Amazonía (región Loreto)" de acuerdo al convenio N 147-PNICP-PIAP-2015. A los revisores por las observaciones realizadas. 


\section{REFERENCIAS BIBLIOGRÁFICAS}

Albert, O. N.; Amaratunga, D.; Haigh, R.P. 2018. Evaluation of the impacts of oil spill disaster on communities and its influence on restiveness in Niger Delta, Nigeria. Procedia engineering, 212: 1054-1061. DOI: https://doi.org/10.1016/j. proeng.2018.01.136

Armenteras, D.; Rodríguez, N. 2014. Dinámicas y causas de deforestación en bosques de Latino América: una revisión desde 1990. Colombia Forestal, 17(2): 233-246. DOI: http:// dx.doi.org/10.14483/udistrital.jour.colomb. for.2014.2.a07

Baruah, P.; Saikia, R.R.; Baruah, P.P.; Deka, S. 2014. Effect of crude oil contamination on the chlorophyll content and morphoanatomy of Cyperus brevifolius (Rottb.) Hassk. Environmental Science and Pollution Research, 21(21): 12530-12538. DOI: https://doi. org/10.1007/s11356-014-3195-y

Brekke, C.; Solberg, A.H. 2005. Oil spill detection by satellite remote sensing. Remote Sensing of Environment, 95(1): 1-13. DOI: https://doi. org/10.1016/j.rse.2004.11.015

Brenner, S. 2015. Oil spill modeling in the southeastern Mediterranean Sea in support of accelerated offshore oil and gas exploration. Ocean Dynamics 65 (12): 1685-1697. DOI: https://doi.org/10.1007/s10236-015-0902-2

Butt, N.; Beyer, H.L.; Bennett, J.R.; Biggs, D.; Maggini, R.; Mills, M.; Possingham, H.P. 2013. Biodiversity risks from fossil fuel extraction. Science, 342(10): 9-10. DOI: https://doi. org/10.1126/science.1237261

Cardoso, G.F.; Souza, C.; Souza-Filho, P.W.M. 2014. Using spectral analysis of Landsat-5 TM images to map coastal wetlands in the Amazon River mouth, Brazil. Wetlands Ecology and Management, 22(1): 79-92. DOI: https://doi. org/10.1007/s11273-013-9324-4
Dourojeanni, M. 2016. Aprovechamiento del barbecho forestal en áreas de agricultura migratoria en ia Amazonía peruana. Revista Forestal del Perú, 14(2):1-33.

Duke, N.C.; Pinzón M.Z.S.; Prada, T.M.C. 1997. Large-scale damage to mangrove forests following two large oil spills in Panama. Biotropica, 29(1): 2-14. DOI: https://doi. org/10.1111/j.1744-7429.1997.tb00001.x

Ekundayo, E.O.; Emede, T.O.; Osayande, D.I. 2001. Effects of crude oil spillage on growth and yield of maize (Zea mays L.) in soils of midwestern Nigeria. Plant Foods for Human Nutrition, 56(4): 313-324. DOI: https://doi. org/10.1023/A:1011806706658

Fakhru'l-Razi, A.; Pendashteh, A.; Abdullah, L.C.; Biak, D.R.A.; Madaeni, S.S.; Abidin, Z.Z. 2009. Review of technologies for oil and gas produced water treatment. Journal of Hazardous Materials, 170(2-3): 530=551. DOI: https:// doi.org/10.1016/j.jhazmat.2009.05.044

Finer, M.; Orta-Martínez, M. 2010. A second hydrocarbon boom threatens the Peruvian Amazon: Trends, projections, and policy implications. Environmental Research Letters, 5(1): 014012. DOI: https://doi.org/10.1088/ 1748-9326/5/1/014012

Finer, M.; Jenkins, C.N.; Pimm, S.L.; Keane, B.; Ross, C. 2008. Oil and gas projects in the Western Amazon: Threats to wilderness, biodiversity, and indigenous peoples. PLOS ONE, 3(8): e2932. DOI: https://doi.org/10.1371/journal. pone. 0002932

Gandhi, G.M.; Parthiban, S.; Thummalu, N.; Christy, A. 2015. NDVI: vegetation change detection using remote sensing and GIS-a case study of Vellore District. Procedia Computer Science, 57: 1199-1210. DOI: https://doi.org/10.1016/j. procs.2015.07.415

Ivanov, A.Y.; Zatyagalova, V.V. 2008. A GIS approach to mapping oil spills in a marine environment. International Journal of Remote 
Sensing, 29(21): 6297-6313. DOI: https://doi. org/10.1080/01431160802175587

Kankara, R.S.; Arockiaraj, S.; Prabhu, K. 2016. Environmental sensitivity mapping and risk assessment for oil spill along the Chennai Coast in India. Marine Pollution Bulletin, 106(12): 95-103. DOI: https://doi.org/10.1016/j. marpolbul.2016.03.022

Laurance, W.F.; Goosem, M.; Laurance, S.G.W. 2009. Impacts of roads and linear clearings on tropical forests. Trends in Ecology and Evolution, 24(12): 659-669. DOI: https://doi. org/10.1016/j.tree.2009.06.009

Millward, A.A.; Kraft, C.E. 2004. Physical influences of landscape on a large-extent ecological disturbance: the northeastern North American ice storm of 1998. Landscape Ecology, 19(1): 99111. DOI: https://doi.org/10.1023/B:LAND. 0000018369.41798.2f

Ministerio de Energía y Minas. 2017. Actividades en explotación de hidrocarburos 2016. (http:// www.minem.gob.pe/minem/archivos/5_\%20 CAP\%202-\%20EXPLOTACION\%20DE\%20HC. pdf). Acceso: 19/07/2020.

Ministerio del Ambiente. 2008. Estándares Nacionales deCalidad Ambiental para el Agua. Decreto Supremo $N^{\circ} 002-2008$ ECA-Agua. (http://www. minam.gob.pe/calidadambiental/wp-content/ uploads/sites/22/2013/10/ds_002_2008_ eca_agua.pdf). Acceso: 19/07/2020.

Ministerio del Ambiente. 2013a. Resolución Ministerial $\mathrm{N}^{\circ}$ 094-2013-MINAM. (http:// www.minam.gob.pe / d is posiciones / resolucion-ministerial-n-094-2013-minam/). Acceso: 19/07/2020.

Ministerio del Ambiente. 2013b. Resolución Ministerial $\mathrm{N}^{\circ}$ 263-2013-MINAM. (http:// www.minam.gob.pe/disposiciones / resolucion-ministerial-263-2013-minam/). Acceso: 19/07/2020.

Ministerio del Ambiente. 2013c. Resolución Ministerial $\mathrm{N}^{\circ}$ 370-2013-MINAM. (http:// www.minam.gob.pe / d isposiciones / resolucion-ministerial-370-2013-minam/rmno-370-2013-minam/). Acceso: 19/07/2020.

Ministerio del Ambiente. 2015. Mapa nacional de cobertura vegetal: memoria descriptiva. MINAM, Lima. 100pp.

Mo, Y.; Kearney, M.S.; Riter, J.C. 2017. Postdeepwater horizon oil spill monitoring of Louisiana salt marshes using landsat imagery. Remote Sensing, 9(6): 547. DOI: https://doi. org/10.3390/rs9060547

Neff, J.M. 2002. Bioaccumulation in marine organisms: effect of contaminants from oil well produced water. Elsevier, Oxford. 468pp.

Nelson, J.R.; Grubesic, T.H. 2020. Oil spill modeling: Mapping the knowledge domain. Progress in Physical Geography: Earth and Environment, 44(1): 120-136. DOI: https://doi. org/10.1177\%2F0309133319897503

Ogbo, E. M.; Zibigha, M.; Odogu, G. 2009. The effect of crude oil on growth of the weed (Paspalum scrobiculatum L.)-phytoremediation potential of the plant. African Journal of Environmental Science and Technology, 3(9): 229-233.

Organization of Petroleum Exporting Countries. 2018. Monthly oil market report February 2018. OPEC, Vienna. 109pp.

Orta, M.; Napolitano, D.A.; MacLennan, G.J.; O'Callaghan, C.; Ciborowski, S.; Fabregas, X. 2007. Impacts of petroleum activities for the Achuar people of the Peruvian Amazon: summary of existing evidence and research gaps. Environmental Research Letters, 2(4): 45006. DOI: https://doi.org/10.1088/17489326/2/4/045006

Orta-Martínez, M.; Finer, M. 2010. Oil frontiers and indigenous resistance in the Peruvian Amazon. Ecological Economics, 70(2): 207-218. DOI: https://doi.org/10.1016/j. ecolecon.2010.04.022

Ozigis, M.S.; Kaduk, J.D.; Jarvis, C.H. 2019. Mapping terrestrial oil spill impact using machine 
learning random forest and Landsat 8 OLI imagery: a case site within the Niger Delta region of Nigeria. Environmental Science and Pollution Research, 26(4): 3621-3635. DOI: https://doi.org/10.1007/s11356-018-3824-y

Palacios Vega, J.; Zárate-Gómez, R.; Minaya Vela, R.; Martín Brañas, M.; Benavides Rios, J. 2019. Predicción de la pérdida de la cobertura vegetal por aumento de áreas urbanas en Iquitos, Perú. Ciencia Amazónica (Iquitos), 7(1): 37-50. DOI: https://doi.org/10.22386/ca.v7i1.263

Powers, B. 2008. Informe sobre avances en los proyectos de reinyección en los lotes $1 A B$ y 8. E-Tech International, New México. 29pp.

Rojas, D.S. 2020. Coca y deforestación en la Amazonía colombiana. Tesis de pre-grado, Universidad Jorge Tadeo Lozano, Facultad de Ciencias Sociales, Bogotá, Colombia. 21pp.

Rosell-Melé, A.; Moraleda-Cibrián, N.; CartróSabaté, M.; Colomer-Ventura, F.; Mayor, P.; Orta-Martínez, M. 2017. Oil pollution in soils and sediments from the Northern Peruvian
Amazon. Science of the Total Environment, 610-611(1): 1010-1019. DOI: https://doi. org/10.1016/j.scitotenv.2017.07.208

$\mathrm{Xu}$, H. 2006. Modification of normalised difference water index (NDWI) to enhance open water features in remotely sensed imagery. International Journal of Remote Sensing, 27(14): 3025-3033. DOI: https://doi. org/10.1080/01431160600589179

Yekeen, S.T.; Balogun, A.L.; Yusof, K.B.W. 2020. A novel deep learning instance segmentation model for automated marine oil spill detection. ISPRS Journal of Photogrammetry and Remote Sensing, 167(9): 190-200. DOI: https://doi. org/10.1016/j.isprsjprs.2020.07.011

Yusta, R.; Muñoa, G.; González-Cresto, C.; RosellMelé, A.; Orta-Martínez, M.; Mayor, P. 2015. Indicadores de la contaminación petrogénica en la Reserva Nacional del Pacaya Samiria. Institut de Ciència i Tecnologia Ambiental, Universitat Autònoma de Barcelona, Barcelona. 311pp.

Recibido: 19 de enero de 2020 Aceptado para publicación: 5 de marzo de 2020

Esta obra está bajo una Licencia Creative Commons Atribución-NoComercial-SinDerivar 4.0 Internacional. 